\title{
Microscanners for optical endomicroscopic applications
}

\author{
Kyungmin Hwang, Yeong-Hyeon Seo and Ki-Hun Jeong*
}

\begin{abstract}
MEMS laser scanning enables the miniaturization of endoscopic catheters for advanced endomicroscopy such as confocal microscopy, multiphoton microscopy, optical coherence tomography, and many other laser scanning microscopy. These advanced biomedical imaging modalities open a great potential for in vivo optical biopsy without surgical excision. They have huge capabilities for detecting on-demand early stage cancer with non-invasiveness. In this article, the scanning arrangement, trajectory, and actuation mechanism of endoscopic microscanners and their endomicroscopic applications will be overviewed.
\end{abstract}

Keywords: MEMS scanner, Microscanner, Endoscopy, Endomicroscopy, Endoscopic catheter

\section{Background}

Over $80 \%$ of all cancers attribute to epithelial tissue and the early stage detection of cancer based on resection tissue or extracted body fluid for histological or cytological examination substantially reduces the death rate [1]. However, conventional biopsy with surgical excision still has some disadvantages such as random sample resection, time-consuming sample preparation, or physical invasiveness. Recently, diverse endomicroscopes combining advanced optical microscopic techniques with clinical endoscopes open up optical biopsy that can deliver many advantages of on-demand detection, precise sampling, and noninvasiveness. Laser scanning fluorescence microscopy such as confocal or multiphoton microscopy has been actively applied for optical biopsy in monitoring cellular metabolism inside highly scattering tissues such as in vivo human skin and more recently optical coherence tomography has also been developed for ophthalmological applications since the early 1990s [2-4].These microscopic techniques are rapidly translated into clinical endoscopic applications. As a result, the compactness of laser scanners remains prerequisite

\footnotetext{
*Correspondence: kjeong@kaist.ac.kr

Department of Bio and Brain Engineering, KAIST Institute of Health

Science and Technology, Korea Advanced Institute of Science

and Technology (KAIST), 602 CMS Building (E16), Gwahak-ro 335,

Yuseong-gu, Daejeon 34141, South Korea
}

for miniaturizing laser-scanning endomicroscopes. For the last decade, Microscanners using micro electromechanical systems (MEMS) technology have been exclusively utilized for endomicroscopic applications. The device compactness allows both an endomicroscopic package smaller than $3 \mathrm{~mm}$ in outer diameter and an operational voltage lower than $40 \mathrm{~V}_{\mathrm{DC}}$. i.e. the maximum voltage limit for human body based on IEC 60601-01. This article provides a mini-review for endomicroscopic MEMS scanners, which covers the scanning arrangements, the scanning trajectories, the actuation mechanisms, and the packaging configuration with their endomicroscopic applications.

\section{Scanning arrangement}

The scanning arrangement exhibits two distinct arrangements of pre-objective or post-objective scanning depending on the position of a MEMS scanner and an objective lens. The pre-objective scanning displays that a laser MEMS scanner is located prior to an objective lens as illustrated in Fig. 1a. This arrangement allows a long working distance between an objective lens and a target sample but it may cause significant off-axis aberration for a deflected scanning beam. In this case, the scan length is determined by multiplying the focal length and the angle of incidence of an input beam. The aberration can be minimized by using a specialized $\mathrm{f}-\theta$ lens, whose 

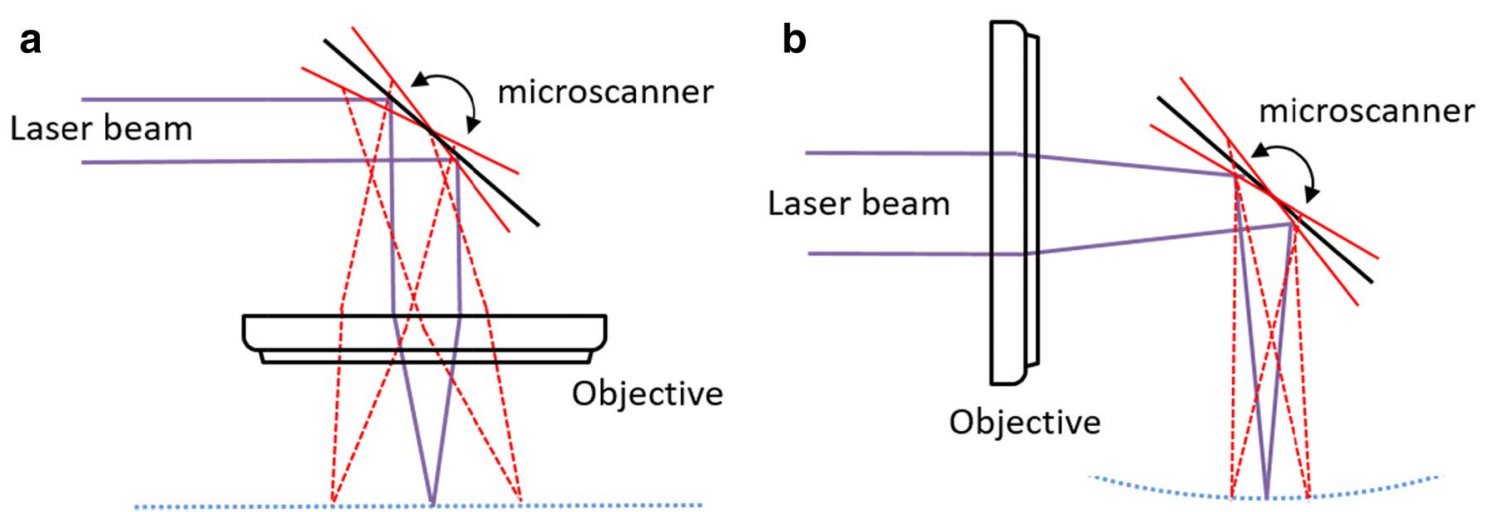

Fig. 1 Scanning arrangements of an endomicroscope depending on the position of a micro-scanner and an objective lens; a pre-objective and b post-objective

diffraction-limited design is optimized for a flat field on the image plane and low distortion [5]. In contrast, the post-objective scanning exhibits that a microscanner is placed after an objective lens as shown in Fig. 1b. Unlike the pre-objective scanning, this arrangement delivers small off-axis aberration as well as high image resolution. However, the working distance becomes short due to the taken space between an objective lens and a target sample and thus the selection of an objective lens with a high NA objective is very limited in practical use.

\section{Scanning trajectory}

The scanning trajectory is governed by spiral scanning, raster scanning, and Lissajous scanning of a laser beam over a scanning area. Two dimensional scanning pattern is obtained by employing two orthogonally scanning waveforms of $\mathrm{x}=\mathrm{x}_{\mathrm{o}} \sin \left(\omega_{\mathrm{x}} \mathrm{t}+\varphi_{\mathrm{x}}\right)$ and $\mathrm{y}=\mathrm{y}_{\mathrm{o}} \sin$ $\left(\omega_{\mathrm{y}} \mathrm{t}+\varphi_{\mathrm{y}}\right)$, where $\mathrm{x}$ and $\mathrm{y}$ are the scanning paths, $\mathrm{x}_{\mathrm{o}}$ and $\mathrm{y}_{\mathrm{o}}$ are the scanning amplitudes, $\mathrm{t}$ is the scanning time, $\omega_{\mathrm{x}}$ and $\omega_{\mathrm{y}}$ are the scanning frequencies, and $\varphi_{\mathrm{x}}$ and $\varphi$ $y$ are the scanning phases on the horizontal and vertical axes, respectively. The spiral scanning of a circular fieldof-view (FOV) is simply achieved by resonating a single scanning fiber under two sine waveforms at $\omega_{x}=\omega_{y}$ and $\Delta \varphi=\pi / 2$. Seibel et al. have first demonstrated a single scanning fiber with a tubular piezoelectric actuator in 2001 [6] and Myaing et al. have successfully demonstrated 2D beam fiber scanning for multi-photon microscopy [7]. The main drawback of spiral scanning is the non-uniform scanning density along a radial direction [8] of the scanned area due to the altered scanning speed as shown in a multiphoton microscopic image of $6 \mu \mathrm{m}$ fluorescent beads in Fig. 2a. In addition, the intrinsic off-axis misalignment of a single fiber readily causes the mechanical coupling between the vertical and horizontal axes of a single scanning fiber [9].
The raster scanning is mainly obtained by using bidirectional scanning waveforms with $\omega_{\mathrm{x}} / \omega_{\mathrm{y}}=N$, where $N$ is a positive integer as shown in Fig. 2b. A laser beam scans laterally from left-to-right at a scanning frequency of $\omega_{x}$, then rapidly moves back to the left, and scans the next line. During this time, the vertical position increases steadily downward at a slow scanning frequency of $\omega_{\mathrm{y}}$. The lateral and vertical scanning frequencies determine the line resolution and the frame rate, respectively. This raster scanning provides a rectangular FOV as well as a simple reconstruction of the scanned images by synchronizing the position of a scanning beam spot with the operational signals. However, raster MEMS scanners have some technical limitations due to high driving voltages or low mechanical stability for the slow axis. In other words, the fast and slow scanning can be often achieved by operating at either resonance or non-resonant frequency. However, the non-resonant motion requires relatively much higher operation voltage than the resonant motion [10]. Rivera et al. have orthogonally attached two piezoelectric bimorphs to a single mode fiber, which shows a resonant motion for the fast lateral axis and a non-resonant motion for the slow vertical axis. Piyawattanametha et al. have successfully demonstrated raster scanning with two resonant MEMS mirrors [11] but the MEMS mirror with a low resonant frequency is vulnerable to the external mechanical shock due to a small spring constant. Do et al. also presented raster scanning endomicroscope using a non-resonant tubular piezoelectric actuator [12]. The non-resonant raster scanner readily changes the FOV with both uniform scanning density and a stable orthogonal shape but it still requires high driving voltages. The bottom image of Fig. $2 b$ indicates the microscopic image of ex vivo mouse tissue based on the raster scanning [10]. 


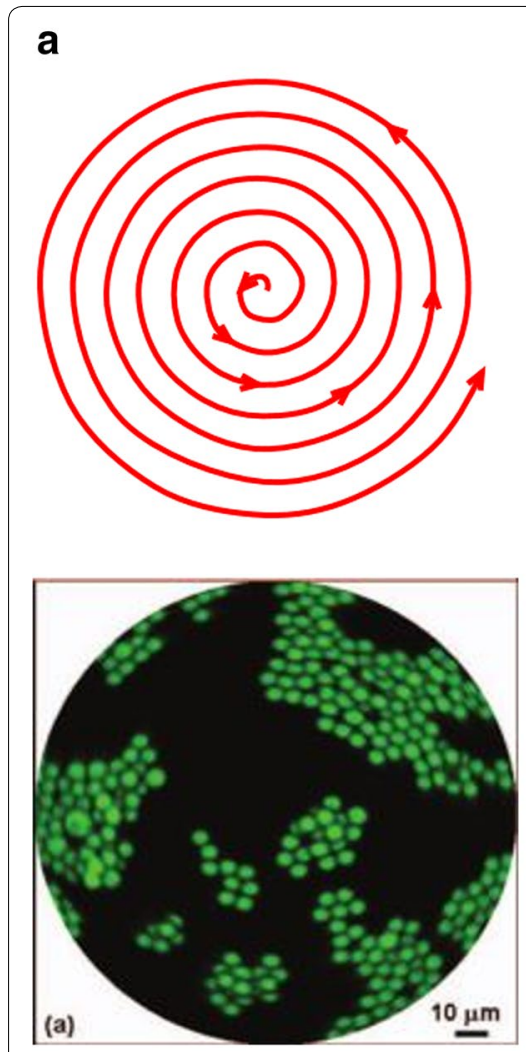

b
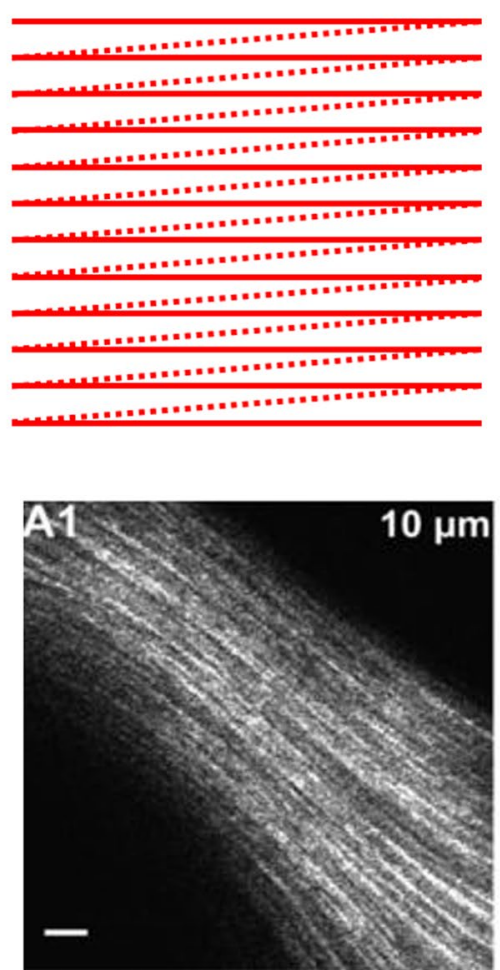

C
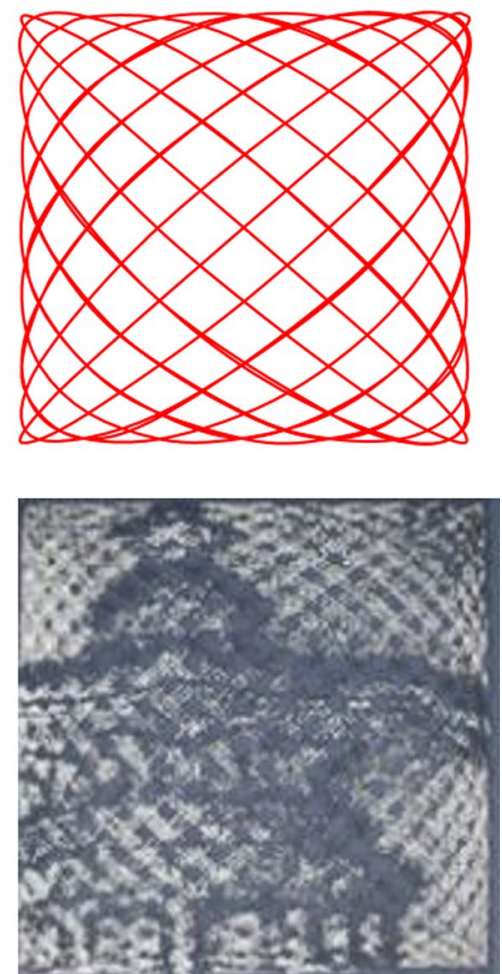

Fig. 2 Scanning trajectories. a Spiral scanning [7], b Raster scanning [10], and c Lissajous scanning [9]. The corresponding scanning pattern in the upper and a representative image in the bottom images

The Lissajous scanning can be achieved when two scanning waveforms have a frequency relation of $\omega_{\mathrm{x}}: \omega_{\mathrm{y}}=n: m$, where $n$ and $m$ are relative prime numbers. The Lissajous scanning also provides a rectangular FOV. Although the scanning pattern and the frame rate are more complex than other scanning patterns, MEMS scanners typically exhibit the Lissajous scanning under high resonant frequencies for both the axes to secure high mechanical stability. Compared to the spiral scanning, the Lissajous scanning also shows high uniform illumination over the full scaned area. Lissajous scanners have been demonstrated by using a MEMS based lens scanner [13] and a fiber scanner [9]. The bottom image of Fig. 2c displays the OCT microscopic image of Korean coin with the detection time of $1.5 \mathrm{~s}$ based on the Lissajous scanning.

\section{Actuation mechanism of microscanners}

The endomicroscopic microscanners mainly divide into scanning mirror, a single optical fiber scanner [7, 9, 14-20], or a lens scanner [13, 21-24]. First, the scanning MEMS mirrors are operated by using electrostatic [2531], electromagnetic [22, 32], or electrothermal [33-39] actuation. An electrostatic force between suspending and fixed electrodes induces the electrostatic actuation, which allows a high scanning resonant frequency but it often requires high operational voltages. Petersen et al. reported the first electrostatic MEMS mirror based on a parallel-plate structure in 1980 [26]. The maximum rotational angle is $\pm 2^{\circ}$ at an operational voltage of $300 \mathrm{~V}$. The parallel-plate structure has a relatively small rotational angle at such high operating voltage due to the pull-in effect [40]. A vertical comb drive overcomes the technical limitation of the parallel-plate actuators. The electrostatic force between vertically located interdigitated comb fingers results in a successful rotation of a silicon mirror with a torsional spring. Aguirre et al. have demonstrated an electrostatic gimbaled 2D MEMS mirror with angular vertical comb drives [27], which offers the mirror rotation angle of $\pm 6^{\circ}$ at over $100 \mathrm{~V}$ (Fig. 3a) The scanning mirror has a circular aperture with a diameter of $1 \mathrm{~mm}$ within the footprint size of $3 \mathrm{~mm} \times 3 \mathrm{~mm}$.

The electromagnetic actuation allows an increased scanning angle under a low operational voltage. The Lorentz force induces attractive and repulsive actuation, which can be selectively generated by changing the direction of a current flow inside active electric coils or permalloy. However, the compulsory existence of electric coils hampers the size reduction of an endomicroscopic 

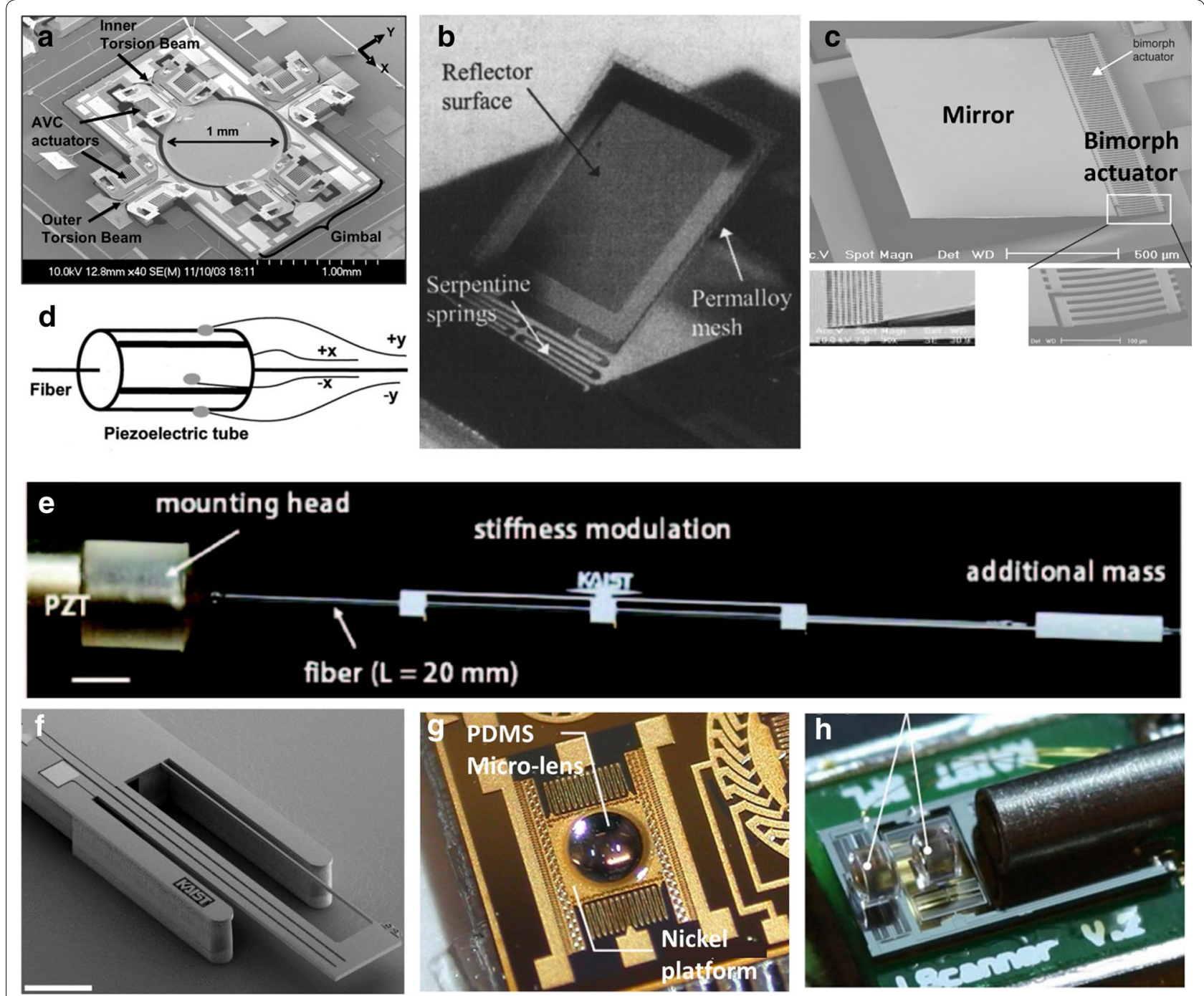

Fig. 3 Microscanners for endomicroscopy. a Electrostatic gimbaled 2D MEMS mirror [27], b Electromagnetic 1D MEMS mirror [32], c 1D single-crystalline silicon MEMS mirror [35], (reproduced by permission of the Institution of Engineering \& Technology) $\mathbf{d}$ spiral PZT scanner [7], e Lissajous fiber scanners using MTSO [14], f Lissajous scanned electrothermal MEMS fiber scanner [15], g electromagnetic MEMS microlens scanner [21], h electrostatic MEMS lens scanner [13]

package. Miller et al. have demonstrated a $1 \mathrm{D}$ micromirror with a rotation angle over $60^{\circ}$ [32] (Fig. 3b). The structure of the scanner is composed of a single-crystalline silicon plane $\left(4 \times 4 \times 0.04 \mathrm{~mm}^{3}\right)$ tethered to the bulk silicon substrate by two serpentine springs. A permalloy layer $(3 \mathrm{~mm} \times 3 \mathrm{~mm})$ which is located on the bottom side of plate induces the magnetic actuation. Kim et al. [22] have also reported an electromagnetic gimballed 2D MEMS mirror. A rectangular MEMS mirror is mounted on a two-axis gimbal platform with folded flexible hinges. The device features a mirror plate of $0.6 \mathrm{~mm} \times 0.8 \mathrm{~mm}$ within a footprint size of $2.4 \mathrm{~mm} \times 2.9 \mathrm{~mm}$ under a post-objective configuration. The resonant frequencies for each axis are 450 and $350 \mathrm{~Hz}$, respectively, and the mechanical rotation angle is around $40^{\circ}$ at $3 \mathrm{~V}_{\mathrm{pp}}$ operational voltages for the fast and slow axes.

The electrothermal actuation can also be achieved by using bimorph microcantilevers of thermally mismatched bilayer films. For instance, a bimorph microcantilever of thin aluminum and silicon dioxide films can induce a large angular motion due to the high stressgradient, which is caused by the mismatch in the thermal coefficient of expansion during Joule heating. The electrothermal micromirrors exhibit a linear relationship 
between a rotation angle and an applied voltage. In particular, a simple configuration of a bimorph cantilever substantially increases the fill factor of a mirror plate. Pan et al. have reported an early model of a 1D electrothermal MEMS mirror [34]. The MEMS mirror is actuated by the bimorph structure composed of $\mathrm{Al}$ and $\mathrm{SiO}_{2}$. The footprint size of MEMS mirror is $1 \mathrm{~mm} \times 1 \mathrm{~mm}$ and the initial bending angle is $17^{\circ}$. They further improved the scan angle up to $37^{\circ}$ by using a $1 \mathrm{D}$ MEMS mirror [35]. In this paper, they used a modified single-crystalline silicon (CSC) micromirror, as shown in Fig. 3c. Jain et al. have reported a two-axis electrothermal MEMS mirror at 2004 [36]. Two axis scanning is realized by using two bimorph thermal actuators: a mirror actuator and a frame actuator. The resonant frequencies of the mirror and frame actuator structures are 445 and $259 \mathrm{~Hz}$, respectively. Sun et al. also have reported a gimbal-less two-axis electrothermal MEMS mirror [37]. Four microactuators on each side increase a scanning area and satisfy lateral-shift-free design suspending the mirror plate $(1 \mathrm{~mm} \times 1 \mathrm{~mm})$. The MEMS mirror scans $30^{\circ}$ at DC $5.5 \mathrm{~V}$ voltage for both $\mathrm{x}$ and y-axes. Wang et al. have demonstrated a 2D electrothermal MEMS mirror, which has four pairs of unique dual S-shaped bimorph structures [38].

The fiber scanning is often realized by using a piezoelectric actuator [7-9, 14, 16-19]. A single optical fiber is precisely mounted on a piezoelectric microactuator or inside a quadrupole piezoelectric tube. The fiber scanner typically operates at the resonant frequencies of an optical fiber along the orthogonal axis and thus the fiber length easily controls the scanning speed. This resonant operation effectively obtains high scanning amplitude below the maximum voltage limit for human body. The fiber scanner often takes spiral scanning because a single optical fiber exhibits the same stiffness for the orthogonal scanning axes, which results in the same resonant frequencies. Myaing et al. have reported the spiral scanning of a single-mode optical fiber at $2.8 \mathrm{kHz}$ resonant frequencies for both the axes [7] (Fig. 3d). Lissajous scanning fiber scanners have been recently developed by operating a piezoelectric tube at two different operating frequencies for both the directions after differentiating the bi-directional spring constants of an optical fiber. For instance, Park et al. have reported Lissajous fiber scanner by using an off-set fiber fragment with micromachined silicon structures to separate the two resonant frequencies [9]. The silicon structures $\left(0.5 \times 0.5 \times 1 \mathrm{~mm}^{3}\right)$ were located at $3.5 \mathrm{~mm}$ and $13.5 \mathrm{~mm}$ of the $20 \mathrm{~mm}$ long fiber apart from the actuator. The scanner has resonant frequencies at 86 and $97 \mathrm{~Hz}$ for $\mathrm{x}$ and $\mathrm{y}$-axes, respectively, and shows the scanning amplitude of 732 and $591.7 \mu \mathrm{m}$ at $40 \mathrm{~V}_{\mathrm{pp}}$. A micromachined tethered silicon oscillator (MTSO) for endoscopic Lissajous fiber scanners has been further demonstrated for the stiffness modulation of a scanning optical fiber in a simple manner [14] (Fig. 3e). Recently, the Lissajous fiber scanning has also been demonstrated by using an electrothermal MEMS fiber scanner. Double hot arm and cold arm structures with a linking bridge and a mounted optical fiber on a silicon fiber groove enable the separation of resonant frequencies of a single optical fiber for Lissajous scanning [15] (Fig. 3f).

Lastly, the lens scanning can also be employed for endomicroscopic applications. Paired lenses on a millimeter scale are mounted on electromagnetic [21] or electrostatic $[13,23]$ microactuators, and they serve as scanning lenses for two dimensional laser scanning. Including commercial glass lenses, a plano-convex polydimethylsiloxane (PDMS) microlenses [21] or gradientindex (GRIN) lenses [13] can serve as a scanning lens. Siu et al. have demonstrated a magnetically actuated MEMS microlens scanner by employing external magnetic field for actuation (Fig. 3g) [21]. The microlens scanner features a plano-convex PDMS microlens and a ferromagnetic nickel platform with a pair of suspension springs. All the components except the PDMS microlens are made of electroplated nickel and thus an external magnetic field induce a magnetic moment to rotate the nickel platform with a periodic focal scanning trajectory. The scanning angle shows $23^{\circ}$ under an external magnetic flux density of $22.2 \times 10^{-3}$ Tesla. An electrostatic MEMS lens scanner has also been demonstrated by Park [13, 24]. The lens scanner has two aspheric glass lenses on orthogonally resonating electrostatic MEMS microstages for Lissajous scanning pattern (Fig. 3h). The scanner has the lateral angle of $\pm 4.6^{\circ}$ at $277 \mathrm{~Hz}$ and the vertical angle of $\pm 4.2^{\circ}$ at $204 \mathrm{~Hz}$ as the lens mass provides high-Q motions at low operating voltages of $5 \mathrm{~V}_{\mathrm{pp}} \mathrm{DC}$ and $10 \mathrm{~V}_{\mathrm{pp}}$ AC.

\section{Packaging configuration}

The endomicroscope package has two different configurations, which are side-looking and forward-looking by incorporating diverse laser scanning microscopy techniques such as optical coherence tomography and confocal/multiphoton microscopy. The side-looking is favourable for endomicroscopic imaging of tubular organs or vasculatures such as intra-artery [41] or respiratory organs [42] and further divides into either en-face or circumferential imaging. The en-face imaging is often achieved by using electrostatic, electromagnetic, or electrothermal actuated MEMS mirrors. Figure 4a shows an 


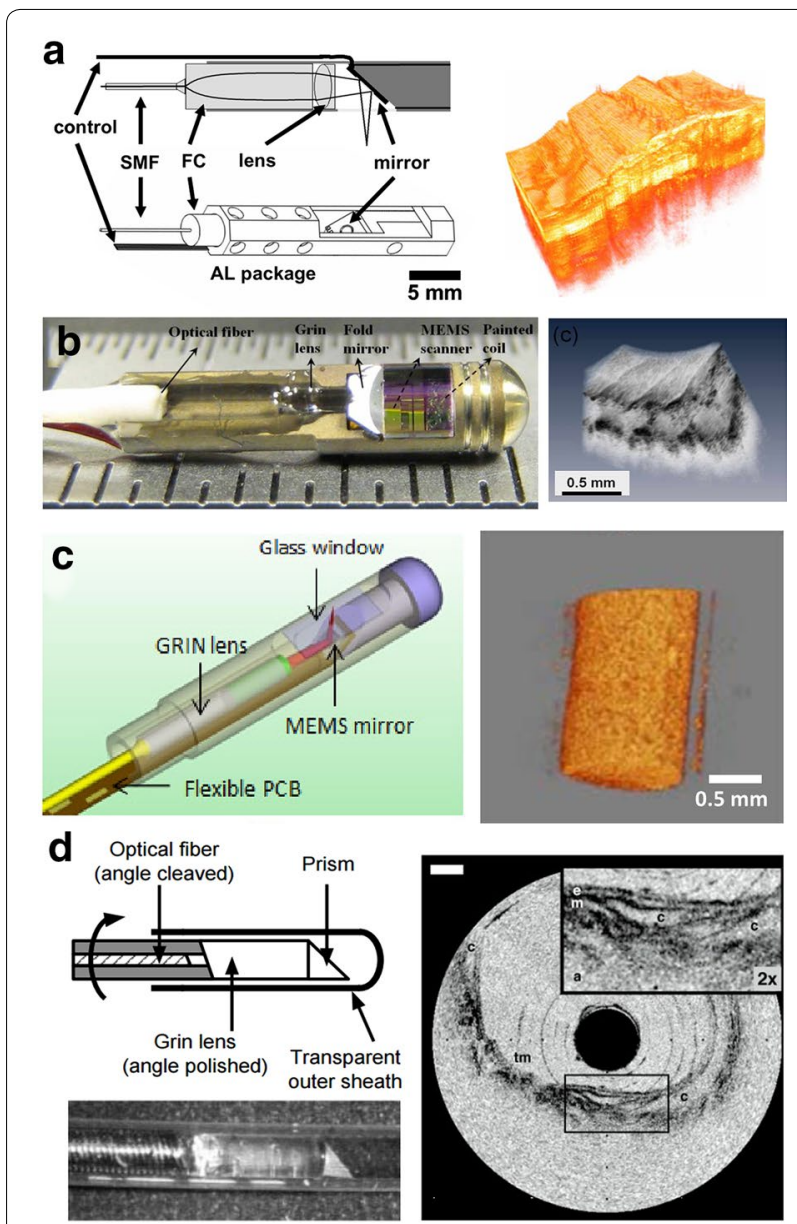

Fig. 4 Side looking endomicroscopy. a Electrostatic MEMS mirror probe. OCT image of the hamster cheek pouch is obtained [27]. b Electromagnetic en-face endomicroscope. OCT image of the finger was obtained [22]. c Electrothermal MEMS mirror probe. OCT image of glass tube filled with milk was obtained [38]. d Circumferential probe with microprism. OCT image of a rabbit trachea was obtained [43]

electrostatic MEMS mirror probe including a MEMS mirror with an aluminium holder, a GRIN lens, an optical fiber, and a small achromatic lens [27]. The MEMS mirror is mounted at $45^{\circ}$ to the optical axis of the lens and the en-face scanner performs post-objective scanning with minimal off-axis aberrations. This fully packaged endoscopic catheter delivers the OCT image of a hamster cheek pouch. Figure $4 \mathrm{~b}$ shows an electromagnetic en-face endomicroscope, where a permanent magnet and wire-wound coils are located at the backside of the mirror plate and inside an endoscopic probe, respectively.
The fully packaged endomicroscopic catheter exhibits $2.8 \mathrm{~mm}$ in outer diameter and $12 \mathrm{~mm}$ in length [22]. The MEMS mirror reflects light toward a specimen through a cylindrical glass window. The catheter was combined with a SD-OCT system to obtain the OCT images of a fingertip. Figure 4c demonstrates an electrothermal MEMS mirror for side-looking and en-face configuration [38]. The endomicroscopic probe consists of a mount base, a GRIN lens, a GRIN lens fiber, and a MEMS mirror with a post-objective arrangement within an outer diameter of $3.5 \mathrm{~mm}$. The electrothermal 2D MEMS mirror successfully offers a raster scanned OCT image of glass tube filled with milk. On the other hand, the circumferential imaging is mainly obtained by rotating a right-angled along the optical axis as described in Fig. 4d [43, 44]. Light from a single optical fiber is focused through a GRIN lens and circumferentially deflects perpendicular to the central axis of an endomicroscopic catheter with a transparent outer sheath by using a rotating microprism, which is indirectly driven by an external [45] or internal micromotor. The circumferential imaging can also be achieved by rotating a prism-fiber module at the distal end [46].

In contrast, the forward-looking configuration facilitates tissue imaging prior to an endoscopic distal end. This configuration offers many benefits, particularly for gastrointestinal applications because the endomicroscopic probe is directly coupled through an accessory channel of conventional clinical endoscopes and thus the scanning laser beam is parallel to an endoscopic camera. This configuration is often achieved by using a fibercoupled quadrupole piezoelectric tube with a graded refractive index lens [20]. Liu et al. have demonstrated endomicroscopic probe with a quadrupole piezotube (2.4 mm outer diameter, $32 \mathrm{~mm}$ length). H.-C. Park et al. also have demonstrated fully assembled with a hypodermic tube housing of $3.2 \mathrm{~mm}$ outer diameter and a $2 \mathrm{~mm}$ diameter GRIN objective and $5 \mathrm{~mm}$ in length as shown in Fig. 5a. The fully packaged endomicroscope inside a gastrointestinal endoscope obtained a 3D OCT image of a mouse ear (Fig. 5a) [9]. This tubular configuration facilitates simple packaging with the precise optical alignment, particularly for forward-viewing endomicroscopic applications. A dual-axis confocal (DAC) endomicroscope has also be developed for forward-looking tissue imaging. DAC is effective to reject out-of-focus scattered light for high axial resolution, particularly in turbid tissue by applying two optical fibers oriented along the intersecting optical axes of two objectives. Liu et al. have demonstrated a dual-axes confocal reflectance microscope [28]. 

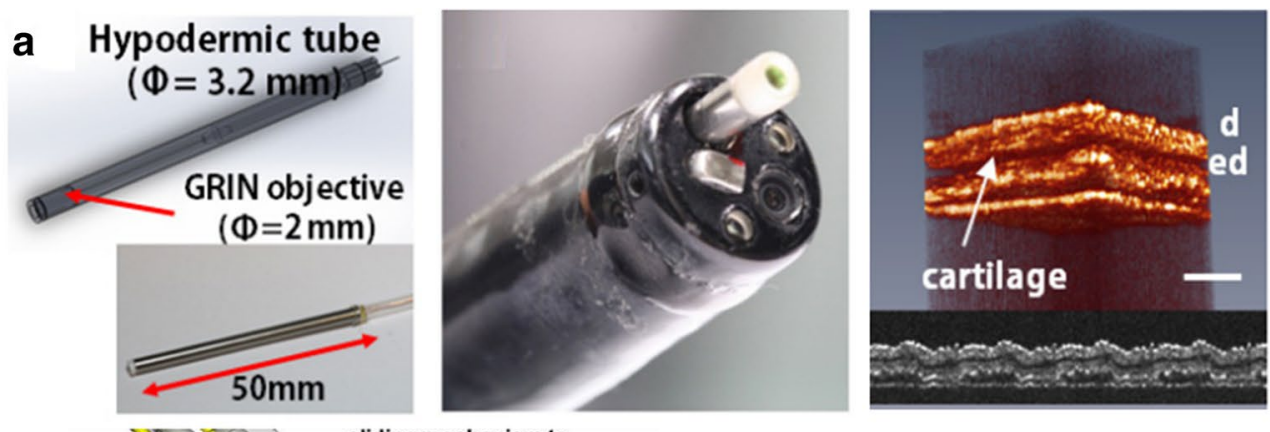

b

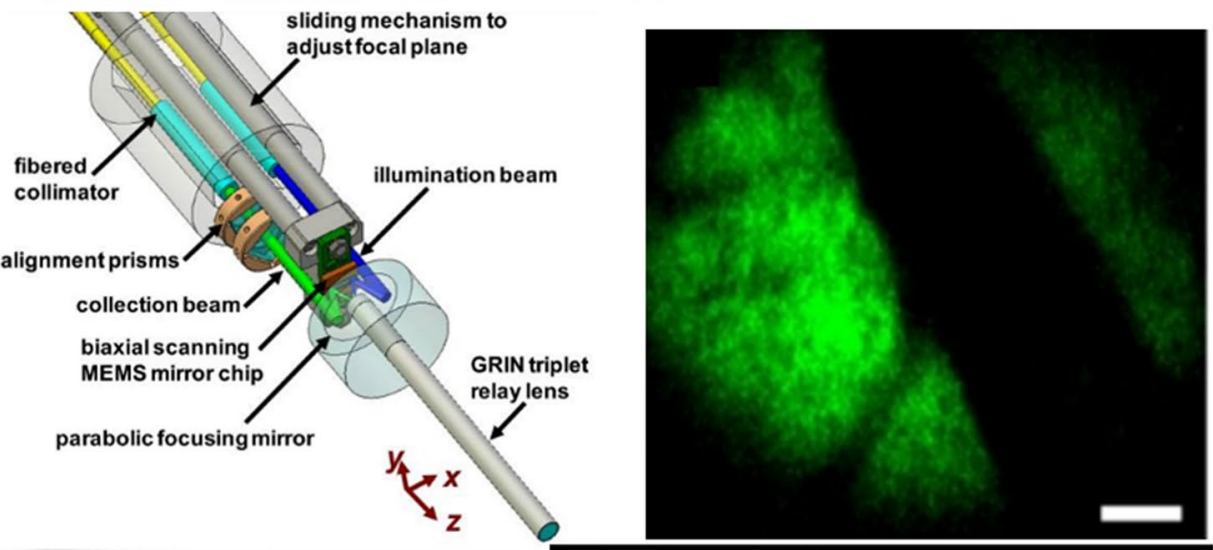

c
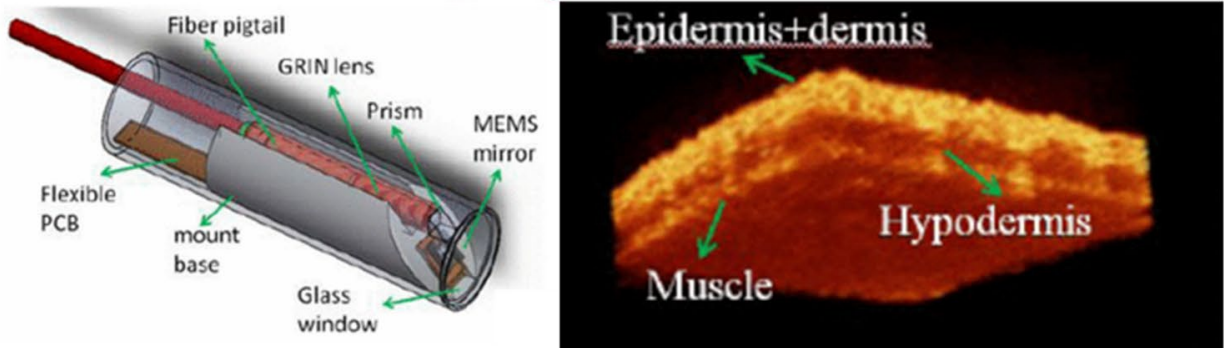

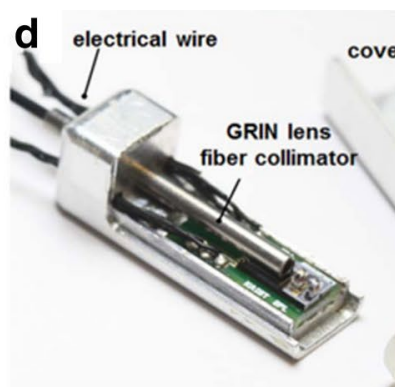

scanning lens

objective lens
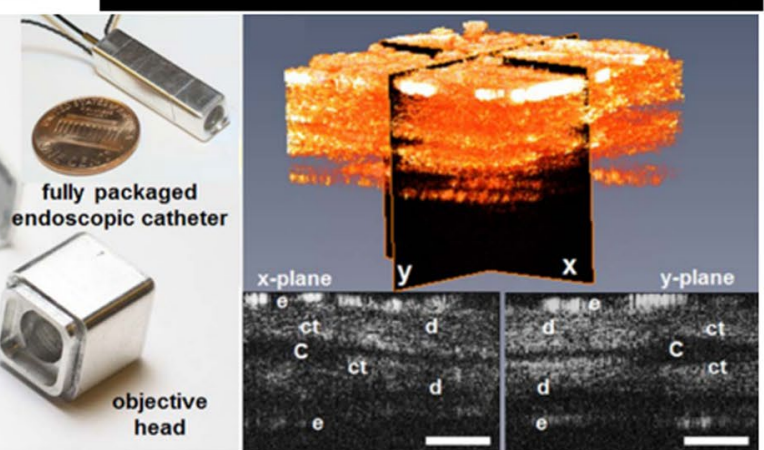

Fig. 5 Forward-looking endomicroscopy. a Schematic and optical image of fully packaged endomicroscope with a fiber scanner. The endomicoscope inside a gastrointestinal endoscope. OCT image of a mouse ear [9]. b Dual-axis confocal endomicroscope. In vivo confocal image of GFPexpressing medulloblastoma in a mouse is obtained [29]. c Forward-viewing OCT imaging probe using a MEMS mirror. OCT image of human nail is obtained [39]. d Electrostatic MEMS lens scanner. OCT image of a mouse ear is obtained [13] 
They further improved a handheld micromirror-scanned dual-axis confocal microscope, as shown in Fig. 5b [29]. GRIN lens is placed at the tip of DAC endomicroscope, where two low NA beams are focused with a crossing angle of $45^{\circ}$ to minimize optical aberrations as well as they provide a long working distance for the post-objective configuration [30]. Two pairs of actuators locate with opposite directions, and Fig. 5b shows in vivo confocal image of GFP-expressing medulloblastoma in a mouse.

The lens scanning has also been developed for forward looking endomicroscopy by using electromagnetic, electrothermal, or electrostatic actuation. Siu et al. have demonstrated a magnetically actuated MEMS microlens scanner assembled with an optical fiber [21]. The microlens scanner is driven by an external AC magnetic field, eliminating chip circuitry, and thermal deformation induced by Joule heating. Duan et al. have demonstrated an electrothermal MEMS actuator for a forward-looking OCT imaging endomicroscope [39]. The probe comprises a fiber-GRIN lens-prism module, a two- axis MEMS mirror whose size is $0.85 \mathrm{~mm} \times 0.85 \mathrm{~mm}$ with flexible PCB, stainless-steel mount, a glass window, and an encapsulation tube. A MEMS mirror is mounted on $45^{\circ}$ slope after the prism. This endomicroscopic probe has the outer diameter of $5 \mathrm{~mm}$ and demonstrates the OCT image of human nail after combining swept-source OCT system as shown in Fig. 5c. An electrostatic MEMS lens scanner also enables 2D optical scanning for forward-looking OCT imaging. The probe consists of the MEMS lens scanner, a printed circuit board (PCB), a GRIN fiber collimator, and objective lens, and an aluminum housing (Fig. 5d) [13]. The MEMS lens scanner mounted on the PCB was aligned along an optical axis on a silicon fiber groove. The pre-objective design of silicon lens holders and silicon fiber groove becomes compact, facilitates the precise optical alignment, and provides a long working distance. The endomicroscopic catheter has an outer dimension of $7 \times 7 \mathrm{~mm}$ with the $5 \mathrm{~mm}$ diameter of the objective lens and successfully demonstrates the SD-OCT image of a mouse ear as shown in Fig. 5d.

\section{Conclusions}

We have overviewed MEMS microscanners for endomicroscopic applications depending on scanning arrangement, trajectories, scanning mechanism, and endoscopic optical packaging configuration. Table 1 shows the summary of endomicroscopic microscanners. The scanning arrangement has two different optical layouts of pre-objective and post objective configuration, which is determined by the position of an objective lens and a microscanner. The pre-objective configuration is effective for a long working distance between the objective lens whereas the post-objective has no off-axis aberration with relatively high image resolution. The scanning trajectory includes spiral, raster, or Lissajous scanning patterns. The spiral scanning, operated by the same resonant frequencies for $x$-and $y$-axes, is beneficial for the quarto-pole piezoelectric tube but not for many other MEMS scanners. The raster scanning can take many advantages for high speed laser scanning endomicroscopy due to the simplicity in both the device operation and the imaging processing. Conventional MEMS scanners deliver the raster scanning but they suffer from high voltage operation for the slow axis or low mechanical stability with the low operational scanning frequency. In contrast, the Lissajous scanners can be often operated with fast scanning frequencies for both the axes whereas the scanning trajectory becomes relatively complicated. This operation accompanies with high mechanical stability and resonant operation with low operational voltages. The endomicroscopic MEMS scanners are categorized into MEMS mirrors, scanning fibers, and lens scanners. Electrostatic, electromagnetic, and electrothermal actuations are commonly utilized for MEMS mirror scanners and MEMS lens scanners. The electrostatic actuation offers high-speed operation with extremely low power consumption but it requires high driving voltages. The electromagnetic actuation delivers a large scanning angle with relatively low driving voltages but it requires the permanent extra magnetic field. The electrothermal scanners can also realize a large scan angle at a low driving voltage but they have intrinsic limitation in high-speed operation due to the cooling time. In addition, the PZT based fiber scanners chiefly operate at the resonant frequencies of a single optical fiber and they performs an effective scanning amplitude below the maximum voltage limit for human body and flexible scanning speed by controlling the length of a fiber. The endomicroscopic packaging is also divided into the side looking and the forward looking. The side-looking imaging provides the transverse images, which are instrumental for tubular intra- organs or vasculatures. This configuration often uses fiber prism assembly and MEMS mirror scanners with $45^{\circ}$, which can serve as an en-face scanner with the post-objective configuration for the minimal off-axis aberration. The forward-looking imaging realizes gastroscopic microscopy by combining with conventional endoscopes because the optical axis is parallel to that of an endoscopic camera. The fiber-coupled PZT tube with a GRIN lens and the lens scanners generally achieves the forward-looking configuration. MEMS technology enables miscellaneous laser scanners, 
Table 1 Microscanner comparison summary

\begin{tabular}{|c|c|c|c|c|c|}
\hline $\begin{array}{l}\text { Packaging } \\
\text { configuration }\end{array}$ & $\begin{array}{l}\text { Scanning } \\
\text { arrangement }\end{array}$ & $\begin{array}{l}\text { Scanning } \\
\text { trajectories }\end{array}$ & Actuation mechanism & Author (year), Journal & Applications (ref) \\
\hline \multirow[t]{7}{*}{ Side-viewing } & \multirow[t]{2}{*}{ Pre-objective } & \multirow[t]{2}{*}{ Line } & $\begin{array}{l}\text { 1D electrostatic MEMS mir- } \\
\text { ror scanner }\end{array}$ & Zara (2003), OL & OCT [25] \\
\hline & & & Micro motor & Adler (2007), Nat Photo & OCT [45] \\
\hline & \multirow[t]{5}{*}{ Post-objective } & Line & $\begin{array}{l}\text { 1D electrostatic MEMS mir- } \\
\text { ror scanner }\end{array}$ & Toshiyoshi (2011), ISOP & OCT [31] \\
\hline & & \multirow[t]{3}{*}{ Raster } & $\begin{array}{l}\text { 2D electromagnetic MEMS } \\
\text { mirror scanner }\end{array}$ & $\operatorname{Kim}(2007)$, OPEX & SD-OCT [22] \\
\hline & & & $\begin{array}{l}\text { 2D electrostatic MEMS mir- } \\
\text { ror scanner }\end{array}$ & Aguirre (2007), OPEX & OCT [27] \\
\hline & & & $\begin{array}{l}\text { 2D electrothermal MEMS } \\
\text { mirror scanner }\end{array}$ & Wang (2013), BOE & OCT [38] \\
\hline & & Lissajous & $\begin{array}{l}\text { 2D electrothermal MEMS } \\
\text { mirror scanner }\end{array}$ & Sun (2010), OPEX & OCT [37] \\
\hline \multirow[t]{21}{*}{ Forward-viewing } & \multirow[t]{19}{*}{ Pre-objective } & \multirow[t]{3}{*}{ Line } & $\begin{array}{l}\text { Quarter-tubular piezoelec- } \\
\text { tric actuator based fiber } \\
\text { scanner }\end{array}$ & Liu (2004), OL & OCT [20] \\
\hline & & & \multirow{2}{*}{$\begin{array}{l}\text { 1D electrothermal MEMS } \\
\text { mirror scanner }\end{array}$} & $\operatorname{Pan}(2001), \mathrm{OL}$ & OCT [34] \\
\hline & & & & Xie (2003), EL & OCT [35] \\
\hline & & \multirow[t]{5}{*}{ Spiral } & \multirow{5}{*}{$\begin{array}{l}\text { Quarter-tubular piezoelec- } \\
\text { tric actuator based fiber } \\
\text { scanner }\end{array}$} & Myaing (2006), OL & TPF [7] \\
\hline & & & & Meinert (2014), OPEX & $\begin{array}{l}\text { Confocal reflec- } \\
\text { tance imaging } \\
{[16]}\end{array}$ \\
\hline & & & & Lurie (2015), OL & OCT-SFE [17] \\
\hline & & & & Zhang (2014), OL & SS-OCT [18] \\
\hline & & & & Xi (2012), OL & OCT-TPF [19] \\
\hline & & \multirow[t]{6}{*}{ Raster } & $\begin{array}{l}\text { Piezoelectric actuator based } \\
\text { fiber scanner }\end{array}$ & Rivera (2011), PNAS & TPF/SHG [10] \\
\hline & & & $\begin{array}{l}\text { Quarter-tubular piezoelec- } \\
\text { tric actuator based fiber } \\
\text { scanner }\end{array}$ & Do (2014), JBO & TPF [12] \\
\hline & & & $\begin{array}{l}\text { 2D electromagnetic MEMS } \\
\text { lens scanner }\end{array}$ & Siu (2007), OPEX & $\begin{array}{l}\text { OCT/Confocal } \\
\text { imaging/TPF [21] }\end{array}$ \\
\hline & & & $\begin{array}{l}\text { 2D Electrostatic MEMS mir- } \\
\text { ror scanner }\end{array}$ & Kumar (2010), BM & $\begin{array}{l}\text { Confocal imaging } \\
\text { [23] }\end{array}$ \\
\hline & & & $\begin{array}{l}\text { 2D electrothermal MEMS } \\
\text { mirror scanner }\end{array}$ & Jain (2004), JSTQ & OCT [36] \\
\hline & & & $\begin{array}{l}\text { Two pair of 1D electro- } \\
\text { thermal MEMS mirror } \\
\text { scanners for each axis }\end{array}$ & Duan (2014), ISBI & SS-OCT [39] \\
\hline & & \multirow[t]{5}{*}{ Lissajous } & \multirow{3}{*}{$\begin{array}{l}\text { Quarter-tubular piezoelec- } \\
\text { tric actuator based fiber } \\
\text { scanner }\end{array}$} & Liang (2012), JBO & TPF [8] \\
\hline & & & & Park (2014), OPEX & OCT [9] \\
\hline & & & & Park (2014), OL & OCT [14] \\
\hline & & & $\begin{array}{l}\text { Electrostatic MEMS lens } \\
\text { scanner }\end{array}$ & Park (2012), OL & OCT [13] \\
\hline & & & $\begin{array}{l}\text { 2D electrothermal MEMS } \\
\text { fiber scanner }\end{array}$ & Seo (2016), OPEX & OCT [15] \\
\hline & \multirow[t]{2}{*}{ Post-objective } & Raster & $\begin{array}{l}\text { 2D electrostatic MEMS mir- } \\
\text { ror scanner }\end{array}$ & Ra (2008), OPEX & $\begin{array}{l}\text { Confocal imaging } \\
\text { [30] }\end{array}$ \\
\hline & & Lissajous & $\begin{array}{l}\text { Two pair of 1D electrostatic } \\
\text { MEMS mirror scanners for } \\
\text { each axis }\end{array}$ & Liu (2010), JBO & $\begin{array}{l}\text { Confocal imaging } \\
\text { [29] }\end{array}$ \\
\hline Non & Post-objective & Raster & $\begin{array}{l}\text { Piezoelectric actuator } \\
\text { based fiber scanner \& } \\
\text { galvanometer-driven } \\
\text { mirror }\end{array}$ & Seibel (2001), ISOP & $\begin{array}{l}\text { Confocal reflec- } \\
\text { tance imaging [6] }\end{array}$ \\
\hline
\end{tabular}


Table 1 continued

\begin{tabular}{llllll}
\hline $\begin{array}{l}\text { Packaging } \\
\text { configuration }\end{array}$ & $\begin{array}{l}\text { Scanning } \\
\text { arrangement }\end{array}$ & $\begin{array}{l}\text { Scanning } \\
\text { trajectories }\end{array}$ & Actuation mechanism & Author (year), Journal & Applications (ref) \\
\hline Non & Pre-objective & Raster & $\begin{array}{l}\text { 2D electrostatic MEMS mir- } \\
\text { ror scanner }\end{array}$ & $\begin{array}{c}\text { Piyawattanametha (2006), } \\
\text { OL TPF [11] }\end{array}$ & 1D electromagnetic MEMS \\
Non & mon & Line & Miller (1997), Opt Eng & [32] \\
\hline
\end{tabular}

which have huge potential for miniaturized imaging applications. The proper use of laser microscanners for optical endomicroscopy will guide and lead more effective clinical applications for early cancer detection of internal organs.

\section{Authors' contributions}

$\mathrm{KH}$ and $\mathrm{YHS}$ carried out literature search and wrote the manuscript. KHJ reviewed/edited the manuscript. All authors read and approved the final manuscript.

\section{Competing interests}

The authors declare that they have no competing interests.

\section{Funding}

This work was supported by a grant of the Korean Health Technology R\&D Project, Ministry of Health \& Welfare, Republic of Korea (HI13C2181, HI16C1111), the Global Frontier Project (2016924609) of the Korea government, and the Ministry of Science ICT \& Future Planning (2016013061).

Received: 5 October 2016 Accepted: 23 December 2016

Published online: 02 January 2017

\section{References}

1. Siegel R, Naishadham D, Jemal A (2012) Cancer statistics, 2012. CA Cancer J Clin 62:10-29

2. Masters BR, So PT, Gratton E (1998) Multiphoton excitation microscopy of in vivo human skin: functional and morphological optical biopsy based on three-dimensional imaging, lifetime measurements and fluorescence spectroscopya. Ann N Y Acad Sci 838:58-67

3. Van Norren D, Van De Kraats J (1989) Imaging retinal densitometry with a confocal scanning laser ophthalmoscope. Vis Res 29:1825-1830

4. Izatt JA, Hee MR, Swanson EA, Lin CP, Huang D, Schuman JS, Puliafito CA, Fujimoto JG (1994) Micrometer-scale resolution imaging of the anterior eye in vivo with optical coherence tomography. Arch Ophthalmol 112:1584-1589

5. Chen M-F, Chen Y-P (2007) Compensating technique of field-distorting error for the $\mathrm{CO}_{2}$ laser galvanometric scanning drilling machines. Int J Mach Tools Manuf 47:1114-1124

6. Seibel EJ, Smithwick QY, Brown CM, Reinhall PG, in EOS/SPIE European biomedical optics week. International Society for Optics and Photonics, 2001, pp 29-39

7. Myaing MT, MacDonald DJ, Li X (2006) Fiber-optic scanning two-photon fluorescence endoscope. Opt Lett 31:1076-1078

8. Liang W, Murari K, Zhang Y, Chen Y, Li M-J, Li X (2012) Increased illumination uniformity and reduced photodamage offered by the Lissajous scanning in fiber-optic two-photon endomicroscopy. J Biomed Opt 17:0211081-0211085

9. Park H-C, Seo Y-H, Jeong K-H (2014) Lissajous fiber scanning for forward viewing optical endomicroscopy using asymmetric stiffness modulation. Opt Express 22:5818-5825
10. Rivera DR, Brown CM, Ouzounov DG, Pavlova I, Kobat D, Webb WW, Xu C (2011) Compact and flexible raster scanning multiphoton endoscope capable of imaging unstained tissue. Proc Nat Acad Sci 108:17598-17603

11. Piyawattanametha W, Barretto RP, Ko TH, Flusberg BA, Cocker ED, Ra H, Lee D, Solgaard O, Schnitzer MJ (2006) Fast-scanning two-photon fluorescence imaging based on a microelectromechanical systems twodimensional scanning mirror. Opt Lett 31:2018-2020

12. Do D, Yoo H, Gweon D-G (2014) Fiber-optic raster scanning two-photon endomicroscope using a tubular piezoelectric actuator. J Biomed Opt 19:066010

13. Park H-C, Song C, Kang M, Jeong Y, Jeong K-H (2012) Forward imaging OCT endoscopic catheter based on MEMS lens scanning. Opt Lett 37:2673-2675

14. Park H-C, Seo Y-H, Hwang K, Lim J-K, Yoon SZ, Jeong K-H (2014) Micromachined tethered silicon oscillator for an endomicroscopic Lissajous fiber scanner. Opt Lett 39:6675-6678

15. Seo Y-H, Hwang K, Park H-C, Jeong K-H (2016) Electrothermal MEMS fiber scanner for optical endomicroscopy. Opt Express 24:3903-3909

16. Meinert T, Weber N, Zappe H, Seifert A (2014) Varifocal MOEMS fiber scanner for confocal endomicroscopy. Opt Express 22:31529-31544

17. Lurie KL, Gurjarpadhye AA, Seibel EJ, Ellerbee AK (2015) Rapid scanning catheterscope for expanded forward-view volumetric imaging with optical coherence tomography. Opt Lett 40:3165-3168

18. Zhang N, Tsai T-H, Ahsen OO, Liang K, Lee H-C, Xue P, Li X, Fujimoto JG (2014) Compact piezoelectric transducer fiber scanning probe for optical coherence tomography. Opt Lett 39:186-188

19. Xi J, Chen Y, Zhang Y, Murari K, Li M-J, Li X (2012) Integrated multimodal endomicroscopy platform for simultaneous en face optical coherence and two-photon fluorescence imaging. Opt Lett 37:362-364

20. Liu X, Cobb MJ, Chen Y, Kimmey MB, Li X (2004) Rapid-scanning forwardimaging miniature endoscope for real-time optical coherence tomography. Opt Lett 29:1763-1765

21. Siu CPB, Zeng H, Chiao M (2007) Magnetically actuated MEMS microlens scanner for in vivo medical imaging. Opt Express 15:11154-11166

22. Kim KH, Park BH, Maguluri GN, Lee TW, Rogomentich FJ, Bancu MG, Bouma BE, de Boer JF, Bernstein JJ (2007) Two-axis magnetically-driven MEMS scanning catheter for endoscopic high-speed optical coherence tomography. Opt Express 15:18130-18140

23. Kumar K, Avritscher R, Wang Y, Lane N, Madoff DC, Yu T-K, Uhr JW, Zhang $X$ (2010) Handheld histology-equivalent sectioning laser-scanning confocal optical microscope for interventional imaging. Biomed Microdevices 12:223-233

24. Park H-C, Song C, Jeong K-H (2010) Micromachined lens microstages for two-dimensional forward optical scanning. Opt Express 18:16133-16138

25. Zara JM, Yazdanfar S, Rao KD, Izatt JA, Smith SW (2003) Electrostatic micromachine scanning mirror for optical coherence tomography. Opt Lett 28:628-630

26. Petersen KE (1980) Silicon torsional scanning mirror. IBM J Res Devel 24:631-637

27. Aguirre AD, Herz PR, Chen Y, Fujimoto JG, Piyawattanametha W, Fan L, Wu MC (2007) Two-axis MEMS scanning catheter for ultrahigh resolution three-dimensional and en face imaging. Opt Express 15:2445-2453

28. Liu JT, Mandella MJ, Friedland S, Soetikno R, Crawford JM, Contag CH, Kino GS, Wang TD (2006) Dual-axes confocal reflectance microscope for distinguishing colonic neoplasia. J Biomed Opt 11:054019 
29. Liu JT, Mandella MJ, Loewke NO, Haeberle H, Ra H, Piyawattanametha W, Solgaard O, Kino GS, Contag CH (2010) Micromirror-scanned dual-axis confocal microscope utilizing a gradient-index relay lens for image guidance during brain surgery. J Biomed Opt 15:026029

30. Ra H, Piyawattanametha W, Mandella MJ, Hsiung P-L, Hardy J, Wang TD, Contag CH, Kino GS, Solgaard O (2008) Three-dimensional in vivo imaging by a handheld dual-axes confocal microscope. Opt Express 16:7224-7232

31. Toshiyoshi H (2011) SPIE MOEMS-MEMS. (International Society for Optics and Photonics, 2011), p 793003-793012

32. Miller RA, Tai Y-C (1997) Micromachined electromagnetic scanning mirrors. Opt Eng 36:1399-1407

33. Xu Y, Singh J, Selvaratnam T, Chen N (2009) Two-axis gimbal-less electrothermal micromirror for large-angle circumferential scanning. IEEE J Sel Top Quant 15:1432-1438

34. Pan Y, Xie H, Fedder GK (2001) Endoscopic optical coherence tomography based on a microelectromechanical mirror. Opt Lett 26:1966-1968

35. Xie T, Xie H, Fedder G, Pan Y (2003) Endoscopic optical coherence tomography with new MEMS mirror. Electron Lett 39:1

36. Jain A, Kopa A, Pan Y, Fedder GK, Xie H (2004) A two-axis electrothermal micromirror for endoscopic optical coherence tomography. IEEE J Sel Top Quant 10:636-642

37. Sun J, Guo S, Wu L, Liu L, Choe S-W, Sorg BS, Xie H (2010) 3D in vivo optical coherence tomography based on a low-voltage, large-scan-range 2D MEMS mirror. Opt Express 18:12065-12075

38. Wang D, Liang P, Samuelson S, Jia H, Ma J, Xie H (2013) Correction of image distortions in endoscopic optical coherence tomography based on two-axis scanning MEMS mirrors. Biomed Opt Express 4:2066-2077
39. Duan C, Zhang X, Wang D, Zhou Z, Liang P, Pozzi A, Xie H (2014) IEEE 11 th international symposium on biomedical imaging (ISBI). (IEEE, 2014), p 1397-1400

40. Nielson GN, Barbastathis G (2006) Dynamic pull-in of parallel-plate and torsional electrostatic MEMS actuators. J Microelectromech Syst 15:811-821

41. Fujimoto J, Boppart SA, Tearney G, Bouma B, Pitris C, Brezinski M (1999) High resolution in vivo intra-arterial imaging with optical coherence tomography. Heart 82:128-133

42. Tearney G, Brezinski M, Fujimoto J, Weissman N, Boppart S, Bouma B, Southern J (1996) Scanning single-mode fiber optic catheter-endoscope for optical coherence tomography. Opt Lett 21:543-545

43. Tearney GJ, Brezinski ME, Bouma BE, Boppart SA, Pitris C, Southern JF, Fujimoto JG (1997) In vivo endoscopic optical biopsy with optical coherence tomography. Science 276:2037-2039

44. Yang J-M, Favazza C, Chen R, Yao J, Cai X, Maslov K, Zhou Q, Shung KK, Wang LV (2012) Simultaneous functional photoacoustic and ultrasonic endoscopy of internal organs in vivo. Nat Med 18:1297-1302

45. Adler DC, Chen Y, Huber R, Schmitt J, Connolly J, Fujimoto JG (2007) Three-dimensional endomicroscopy using optical coherence tomography. Nat Photonics 1:709-716

46. Tran PH, Mukai DS, Brenner M, Chen Z (2004) In vivo endoscopic optical coherence tomography by use of a rotational microelectromechanical system probe. Opt Lett 29:1236-1238

\section{Submit your manuscript to a SpringerOpen ${ }^{\odot}$ journal and benefit from:}

- Convenient online submission

- Rigorous peer review

- Immediate publication on acceptance

- Open access: articles freely available online

- High visibility within the field

- Retaining the copyright to your article

Submit your next manuscript at springeropen.com 